\title{
FLOWER ROUNDABOUTS AND DOUBLE-LANE ROUNDABOUTS: A COMPARATIVE PERFORMANCE ANALYSIS
}

\author{
O. GIUFFRÈ ${ }^{1}$, A. GRANÀ2${ }^{2}$ T. GIUFFRÈ ${ }^{3}$, R. MARINO ${ }^{4}$, \\ S. MARINO 5
}

\begin{abstract}
In the paper, a choice criterion between flower roundabouts and double-lane roundabouts is proposed, focusing on operational benefits that can derive from one scheme over the other, and outlining a general framework for benefit-cost analysis. In order to assess operational benefits of innovative roundabouts over modern roundabouts, a comparative analysis was made. Capacity was estimated using gap-acceptance models. In detail, assuming the dichotomic shifted negative exponential distribution to model headways in circulating streams, the Hagring formula was adjusted to obtain entry capacity estimations at roundabout approaches where entering vehicles face one or two conflicting flows. Based on the control delay, the suitability domains and indifference areas were constructed. Thus, a sensitivity analysis to changes in traffic demand for operational benefits of flower roundabouts over double-lane roundabouts was carried out and discussed. At last, evidence for new installations and conversion of existing roundabouts can be found.
\end{abstract}

Keywords: double-lane roundabout, flower roundabout, entry capacity, delay.

\section{INTRODUCTION TO THE OPERATIONAL ANALYSIS OF ROUNDABOUTS}

Nowadays, many types of circular intersections are widely employed at different levels within the road network. Double-lane roundabouts can represent an appropriate design solution when high capacity and improved traffic performances have to be achieved. Recently, schemes of roundabouts with innovative layout have been developed and many of them are already in operation around the world. Among innovative roundabouts, the turbo roundabouts introduced by Fortuijn [1] and the flower roundabouts

1 Department of Civil, Environmental, Aerospace, Materials Engineering, Università di Palermo, Viale delle Scienze Ed.8, Palermo, 90128, Italy, e-mail: orazio.giuffre@unipa.it

2 Department of Civil, Environmental, Aerospace, Materials Engineering, Università di Palermo, Viale delle Scienze Ed. 8, Palermo, 90128, Italy, e-mail: anna.grana@unipa.it

3 Faculty of Engineering and Architecture, Università Kore di Enna, Cittadella Universitaria, 26, Enna 94100, Italy, e-mail: tullio.giuffre@unikore.it

4 Department of Energy, Information Engineering and Mathematical Models, Università di Palermo, Viale delle Scienze Ed. 8, Palermo, 90128, Italy, e-mail: roberta-marino@libero.it

5 Department of Civil, Environmental, Aerospace, Materials Engineering, Università di Palermo, Viale delle Scienze Ed. 8, Palermo, 90128, Italy, e-mail: sergio.marino@unipa.it 
patented by Tollazzi, Renčelj, Turnšek [2] can be a valid alternative to the double-lane roundabouts when the same space requirements are requested.

Entry capacity models for modern roundabouts have evolved with reference to the roundabout categories (single-, double-, multi-lane roundabouts) progressively introduced (Rodegerdts et al. [3]). Differently from roundabouts, only a few methods have been presented for capacity estimation at turbo roundabouts, and no entry capacity models have been developed specifically for flower roundabouts. However, literature reports several studies focused on methods to evaluate performances of new types of roundabouts or roundabouts with specific modes of operation (e.g. see Brilon [4], Giuffrè, Granà, T. Giuffrè, Marino [5][6], Lin, Xu, Fang, Wang, Li [7], Corriere, Guerrieri [8], Mauro, Guerrieri [9][10], Yao, Xu, Qin [11], Yap, Gibson, Waterson [12]).

Capacity models for stop-controlled intersections and modern roundabouts can be applied for performance assessments at innovative roundabouts. These models are generally classified as empirical regression models (starting from Kimber, Coombe [13]), and gap-acceptance capacity models (see e.g. Brilon, Wu, Bondzio [14]; HCM [15]). The first models are based on regression using data collected from currently operating and congested intersections; these models usually embrace relationships between geometric design features and measures of capacity and/or delay (with regard to roundabouts see e.g. Brilon, Vandehey [16]; Pratelli, Al-Madani [17]; Al-Madani, [18]). On the contrary, gap-acceptance models take into account both geometric features and user behavioral aspects, the latter expressed by critical gap and follow-up time (Mauro [19]). Moreover, gap-acceptance models require identifying the probability distribution of arrival headways for successive vehicles in major traffic streams. When major-stream vehicles are moving very close together, minor-stream vehicles can enter the intersection when the gap after the last vehicle of the platoon meets or exceeds the critical gap (Tanner [20]). In the case of turbo roundabouts, where different entering modes are coexisting, application of capacity models assuming the same arrival headway distribution for each circulating stream has to be preferred (see Giuffrè, Granà, S. Marino [21]).

\subsection{How to ANALYZE PERFORMANCES AT INNOVATIVE ROUNDABOUTS?}

Implementation of an innovative roundabout (a turbo roundabout or a flower roundabout) instead of a double-lane roundabout requires convenience assessment with reference to safety, operational and environmental benefits. This issue is introduced in section 4 .

From the operational point of view, estimation of performances at innovative roundabouts can result complex due to behavior imposed on users by the geometric and functional design of the intersection layout. Flower roundabouts, indeed, are characterized by physically separated lanes for right turning vehicles; thus the ring is mostly used by through and left turning vehicles. In a previous paper, a comparative performance analysis of basic turbo roundabouts vs double-lane roundabouts was developed (Giuffrè, Granà, S. Marino [21]). Research assumptions regarded both the arrival process in 
major streams and gap-acceptance capacity models. Since a bunched exponential distribution was selected for the major stream headways, the Hagring model was applied for estimations of entry capacity. Indeed, Hagring [22] calculated entry capacity for a minor traffic stream hindered by major streams, each of them characterized by a Cowan's M3 headway distribution (Cowan [23]; Vasconcelos, Silva, Seco, Silva [24]). Moreover, the Hagring model allows to consider, for each circulating lane, different values of behavioral parameters, minimum headway and circulating traffic flow.

In this paper, the model introduced above was applied to compare operational performances of flower roundabouts and double-lane roundabouts (Figure 1). According to Italian guidelines [25], the roundabouts selected to compare operational performances are referable to design solutions intermediate between the compact roundabouts and the conventional roundabouts; see Table 1 for some elements of roundabout geometry according to Italian guidelines [25].

3

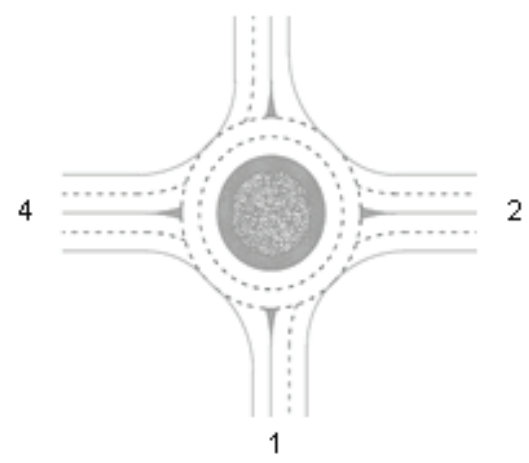

a) double lane roundabout
3

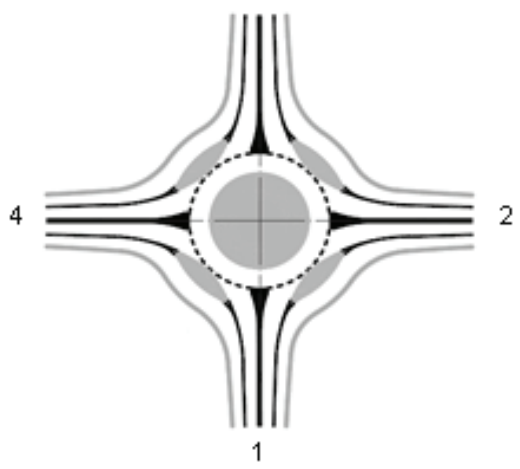

b) flower-roundabout

Fig. 1. Examples of double-lane roundabout (a) and flower roundabout (b)

Suitability domains were constructed for the two selected roundabouts in undersaturated traffic conditions only. Although other studies have assumed the degree of saturation as comparison criterion for evaluating operational benefits of the innovative roundabouts over the modern roundabouts (see e.g. Mauro, Branco [26]; Giuffrè, Granà, S. Marino [27]), the control delay was used here as comparison criterion due to its relationship with the level of service.

This paper is organized as follows: the proposed method to assess and compare the two roundabouts in Figure 1 in terms of operating performances is described in section 2, whereas the outcomes of the performance evaluations between flower roundabouts and double-lane roundabouts under different demand are summarized in section 3 . Beyond operational parameters further aspects such as safety and environmental issues should be considered to guide decisions about new installations and/or conversions of 
existing roundabouts into innovative design solutions; thus an overview of benefits and costs associated with the innovative roundabout treatments is discussed in section 4 . Results and conclusive remarks will be presented and commented in section 5 .

Table 1

Design elements for roundabouts and roundabout category

\begin{tabular}{|c|c|c|c|c|}
\hline \multirow{2}{*}{$\begin{array}{c}\text { Geometric } \\
\text { element }\end{array}$} & \multirow{2}{*}{$\begin{array}{c}\text { entry } \\
\text { lanes }\end{array}$} & $\begin{array}{c}\text { mini-roundabout } \\
14 \mathrm{~m} \leq \mathrm{D}_{\mathrm{o}}<25 \mathrm{~m}\end{array}$ & $\begin{array}{c}\text { compact- } \\
\text { roundabout } \\
25 \mathrm{~m} \leq \mathrm{D}_{\mathrm{o}}<40 \mathrm{~m}\end{array}$ & $\begin{array}{c}\text { conventional- } \\
\text { roundabout } \\
\mathrm{D}_{\mathrm{o}} \geq 40 \mathrm{~m}\end{array}$ \\
\cline { 3 - 5 } & $7-8$ & 7 & 6 \\
\hline $\begin{array}{c}\text { Circular } \\
\left.\text { roadway }{ }^{*}\right)\end{array}$ & 2 & $8.5-9$ & $8.5-9$ & 9 \\
\cline { 2 - 5 } & 1 & 3.5 & 3.5 & 3.5 \\
\hline \multirow{2}{*}{$\begin{array}{c}\text { Entry } \\
\text { approach }\end{array}$} & 2 & 6 & 6 & 6 \\
\hline \multicolumn{2}{|c|}{ Exit [m] } & 4 & 4.5 & 4.5 \\
\hline \multicolumn{2}{c|}{$\begin{array}{c}\text { Central island } \\
\text { treatment }\end{array}$} & $\begin{array}{c}\text { Fully traversable } 14 \leq \mathrm{D}_{\mathrm{o}}<18 \\
\text { Partially traversable } \\
18 \leq \mathrm{D}_{\mathrm{o}}<25\end{array}$ & Raised curb & - \\
\hline
\end{tabular}

$\mathrm{D}_{\mathrm{o}}$ : outer diameter of roundabout; ${ }^{(*)}$ one-lane only.

\section{Research Assumptions for Operational Analysis at Roundabouts}

Gap-acceptance models were applied for entry capacity estimations. The methodology required the identification of traffic volumes entering the roundabout, including the hourly flow rate for each maneuvre. Traffic situations were characterized by the corresponding o/d matrices (as traffic demand percentages from a leg to any other leg). Since many of design features of traditional and innovative roundabouts in rural and suburban areas reflect those in urban areas, analysis was made without any references to the context where the roundabout is installed. Steps and actions of the method applied to compare double-lane roundabouts and flower roundabouts are:

\section{Step action}

1 specification of the probability distribution to model the arrival process in major streams and consequent assumption of the headway distribution in circulating traffic flows;

2 choice of the model for estimating entry capacity;

3 adaptation of the selected model to the characteristics of the roundabouts under examination;

4 assumptions on the values of gap-acceptance parameters $\left(T_{c}\right.$ and $\left.T_{f}\right)$ and their distinction by leg and entry lane; 
5 assumptions on percentages of entry lane selection;

6 evaluations of operational benefits of innovative roundabouts vs double-lane roundabouts.

Step 1. For the roundabouts under examination, the dichotomic shifted negative exponential distribution (M3) mentioned above was adopted as the headway distribution in circulating traffic streams; it takes into account the bunched vehicles.

Step 2. Different models consistent with the M3 headway distribution can be considered for estimating entry capacity. The formula developed by Hagring [22] represents a capacity model appropriate for multi-lane roundabouts (where entering vehicles face circulating streams in which vehicles drive on one or two lanes); indeed, it includes behavioral and traffic parameters specified for each conflicting stream. Thus, the capacity of each entry lane is the capacity of a minor stream entering the roundabout and facing independent major streams, each of them characterized by a Cowan's M3 headway distribution. Each entry lane capacity was then calculated by applying the Hagring formula:

$$
C_{e}=3600 \cdot \sum_{j} \frac{\varphi_{j} \cdot Q_{c, j}}{3600-\Delta_{j} \cdot Q_{c, j}} \cdot \prod_{k}\left(\frac{3600-\Delta_{k} \cdot Q_{c, k}}{3600}\right) \cdot \frac{\exp \left[-\sum_{l} \frac{\varphi_{l} \cdot Q_{c, l}}{3600-\Delta_{l} \cdot Q_{c, l}} \cdot\left(T_{c, l}-\Delta_{l}\right)\right]}{1-\exp \left(-\sum_{m} \frac{\varphi_{m} \cdot Q_{c, m}}{3600-\Delta_{m} \cdot Q_{c, m}} \cdot T_{f, m}\right)}
$$

where:

$\mathrm{C}_{\mathrm{e}}=$ entry lane capacity $[\mathrm{pcu} / \mathrm{h}]$;

$\varphi_{-}=$Cowan's M3 parameter that is the free traffic proportion within the major stream; the Tanner bunching model was used for $\varphi$ estimations [20];

$\mathrm{Q}_{\mathrm{c},}=$ = conflicting traffic flow $[\mathrm{pcu} / \mathrm{h}]$;

$\mathrm{T}_{\mathrm{c}_{-}}=$critical gap for circulatory lane $[\mathrm{s}]$;

$\mathrm{T}_{\mathrm{f},-}=$ follow-up time, $[\mathrm{s}]$

$\Delta_{-}=$minimum headway of circulating traffic $[\mathrm{s}]$;

$\mathrm{j}, \mathrm{k}, \mathrm{l}, \mathrm{m}=$ indices for conflicting lanes (differing in mathematical form, but repeatedly representing the same lanes).

Step 3. To compare flower roundabouts and double-lane roundabouts (Figure 1), two circulating traffic streams were identified on the ring of the double-lane roundabout; for both roundabouts under examination it was also assumed that the outer entering flow included vehicles leaving the intersection at the approach located just after the subject entry. Table 2 shows capacity formulas for double-lane roundabout and flower 


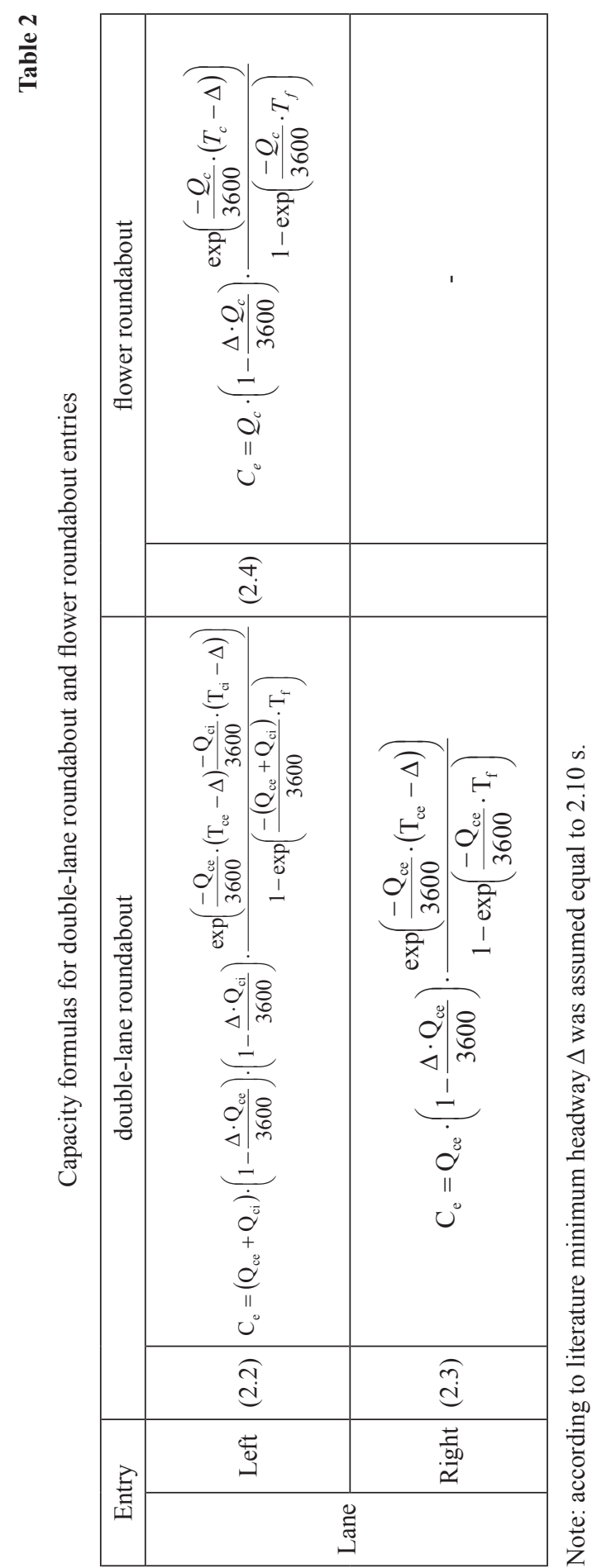


roundabout entries. Considering the double-lane roundabout entry, left-lane capacity was estimated by eq. 2.2 including two circulating traffic flows, whereas right-lane capacity was estimated by eq. 2.3 including the circulating traffic flow in the outer lane of the ring in front of the subject entry. Considering the flower roundabout entry, left-lane capacity was estimated by eq. 2.4 where the only traffic variable is the circulating flow in front of the subject entry. Since at flower roundabouts right turning vehicles use a dedicated lane and do not face conflicting streams, no entry capacity estimations were made for right lanes at entries.

Step 4. Assumptions on the values of the gap-acceptance parameters $\left(\mathrm{T}_{\mathrm{c}}\right.$ and $\left.\mathrm{T}_{\mathrm{f}}\right)$ and the distinction of them by leg and entry lane were made as described in Giuffrè, Granà, $S$. Marino [21]. Table 3 shows gap-acceptance parameters $\left(T_{c}\right.$ and $\left.T_{f}\right)$; values here considered to perform the comparison. It should be noted that two values of critical gap were used for the left entry lanes at double-roundabouts: one for the inner circulating lane $\left(\mathrm{T}_{\mathrm{ci}}\right)$ and another for the outer circulating lane $\left(\mathrm{T}_{\mathrm{ce}}\right)$. In the other cases where entering vehicles faced an antagonist traffic stream, only a $T_{c}$ value was used.

Table 3

Gap acceptance parameters for double-lane and flower roundabout entries

\begin{tabular}{|c|c|c|c|c|c|c|}
\hline \multirow{2}{*}{ Entry } & \multirow{2}{*}{ Lane } & \multicolumn{3}{|c|}{ double-lane } & \multicolumn{2}{c|}{ flower } \\
\cline { 3 - 7 } & & $\mathrm{T}_{\mathrm{ci}}$ & $\mathrm{T}_{\mathrm{ce}}$ & $\mathrm{T}_{\mathrm{f}}$ & $\mathrm{T}_{\mathrm{c}}$ & $\mathrm{T}_{\mathrm{f}}$ \\
\hline \multirow{2}{*}{ All } & Left & 3.19 & 3.03 & 2.26 & 3.74 & 2.13 \\
\cline { 2 - 7 } & Right & - & 3.74 & 2.13 & - & Follow up time [s] \\
\hline
\end{tabular}

Step 5. Assumptions were also made with regard to the entry lane selection percentages at flower roundabouts:

- right-turning vehicles: $90 \%$ from right-entry lane;

- right-turning vehicles: $10 \%$ from left-entry lane at all the legs.

Step 6. Operational benefits of a flower roundabout over a double-lane roundabout were evaluated using the control delay as comparison criterion, since it is related to the level of service. The control delay experienced by entering users was made using the model proposed by HCM [15] (see chapter 21 eq. 21-17). Specifically, the control delay for flower roundabouts was computed as the weighted mean value of the mean control delay $d_{i}$ at each entry lane. No computation of $d_{i}$ was made for the right lane at each flower roundabout entry where $d_{i}=0$. At double-lane roundabouts, where the preselection of entering lane (although desiderable) is not mandatory, the delay experienced by users was computed as the weighted mean of the mean control delay at each entry, 
introducing into the analytical model above mentioned the entry capacity as a whole $\left(\mathrm{C}_{\mathrm{e}, \text { left }}+\mathrm{C}_{\mathrm{e}, \text { right }}\right)$ and the corresponding degree-of-saturation.

\subsection{Characterization of Suitability Domains}

The operational comparison between the layouts in Figure 1 was made by means of suitability domains under undersaturated conditions. Results of this comparison are presented in section 3 .

The representation of the suitability domains was made by a graph where $\mathrm{x}$-axis represents the total entering traffic flows from legs 2-4 $\left(\mathrm{Q}_{\mathrm{e} 2}+\mathrm{Q}_{\mathrm{e} 4}\right)$ and $\mathrm{y}$-axis represents the total entering traffic flows from legs 1-3 $\left(\mathrm{Q}_{\mathrm{e} 1}+\mathrm{Q}_{\mathrm{e} 3}\right)$. In order to represent balanced conditions at entries, $\mathrm{Q}_{\mathrm{e} 1}$ was set equal to $\mathrm{Q}_{\mathrm{e} 3}$, as well as $\mathrm{Q}_{\mathrm{e} 2}$ was set equal to $\mathrm{Q}_{\mathrm{e} 4}$. Moreover, situations in which $\left(\mathrm{Q}_{\mathrm{e} 2}+\mathrm{Q}_{\mathrm{e} 4}\right)<\left(\mathrm{Q}_{\mathrm{e} 1}+\mathrm{Q}_{\mathrm{e} 3}\right)$ were excluded from the graphs, because the symmetry of the graph respect to the diagonal passing through the origin was found; indeed, the same distribution of entering flows to their destinations was assumed for all the legs (see for example Figure 2).

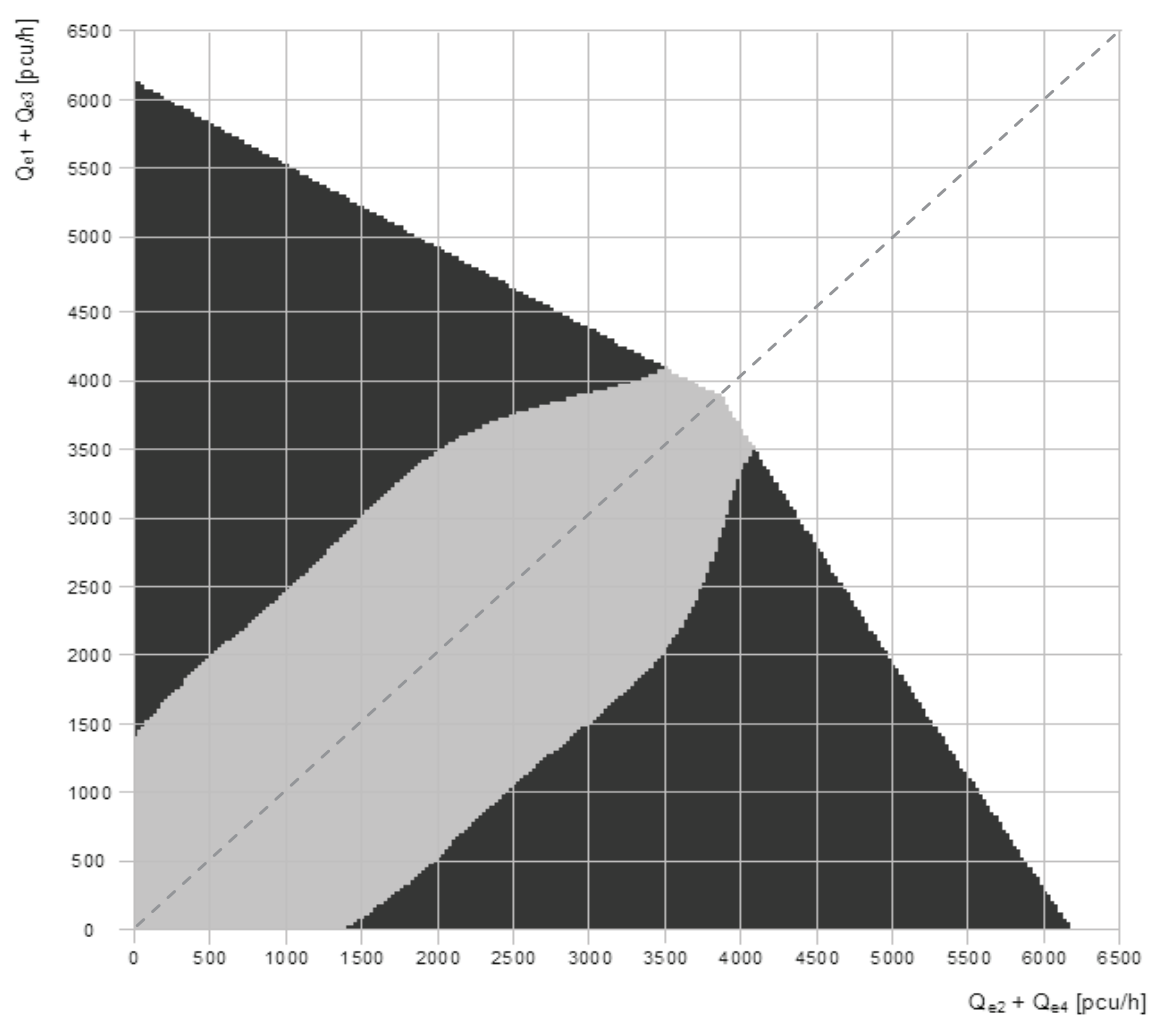

Fig. 2. An example of suitability domain 
Suitability areas for the compared roundabouts were identified according to the following notation: 1) the gray area highlighted situations at the double-lane roundabouts with delays less than $50 \%$ of those observed at the flower roundabouts under the same traffic volumes; 2) the dark gray area highlighted cases at the flower roundabouts with delays less than $50 \%$ of those observed at the double-lane roundabouts.

Situations with delays in one of the two roundabouts never less than $50 \%$ of those observed at the other intersection, that is without clear benefits of the one roundabout over the other one, were represented with a shade of gray intermediate between those above introduced.

\section{Comparison between Flower roundabouts and Double-lane Roundabouts}

The method explained in section 2 was applied to compare performances between flower roundabouts and double-lane roundabouts (see Figure 1). Different traffic situations were examined. Table 4 summarizes the origin/destination matrices (traffic flows in percentage) considered in this study; an increase of $10 \%$ was applied to the percentages of right turning vehicles coming from legs (from $40 \%$ in the case a to $70 \%$ in the case d), whereas left turners and through vehicles were equally distributed with regard to their destinations. It has to be noted that in all the cases here explored the movements with the same origin and destination are excluded.

Table 4

O-D matrices of traffic flows (\%)

\begin{tabular}{c|c|c|c|c}
$\mathrm{O} / \mathrm{D}$ & 1 & 2 & 3 & 4 \\
\hline 1 & 0 & 0.40 & 0.30 & 0.30 \\
\hline 2 & 0.30 & 0 & 0.40 & 0.30 \\
\hline 3 & 0.30 & 0.30 & 0 & 0.40 \\
\hline 4 & 0.40 & 0.30 & 0.30 & 0
\end{tabular}

Case a

\begin{tabular}{c|c|c|c|c}
$\mathrm{O} / \mathrm{D}$ & 1 & 2 & 3 & 4 \\
\hline 1 & 0 & 0.50 & 0.25 & 0.25 \\
\hline 2 & 0.25 & 0 & 0.50 & 0.25 \\
\hline 3 & 0.25 & 0.25 & 0 & 0.50 \\
\hline 4 & 0.50 & 0.25 & 0.25 & 0
\end{tabular}

Case b

\begin{tabular}{c|c|c|c|c}
$\mathrm{O} / \mathrm{D}$ & 1 & 2 & 3 & 4 \\
\hline 1 & 0 & 0.60 & 0.20 & 0.20 \\
\hline 2 & 0.20 & 0 & 0.60 & 0.20 \\
\hline 3 & 0.20 & 0.20 & 0 & 0.60 \\
\hline 4 & 0.60 & 0.20 & 0.20 & 0
\end{tabular}

Case c

\begin{tabular}{c|c|c|c|c}
$\mathrm{O} / \mathrm{D}$ & 1 & 2 & 3 & 4 \\
\hline 1 & 0 & 0.70 & 0.15 & 0.15 \\
\hline 2 & 0.15 & 0 & 0.70 & 0.15 \\
\hline 3 & 0.15 & 0.15 & 0 & 0.70 \\
\hline 4 & 0.70 & 0.15 & 0.15 & 0
\end{tabular}

Case d 
The suitability domains for flower roundabouts and double-lane roundabouts are depicted in Figure 3.

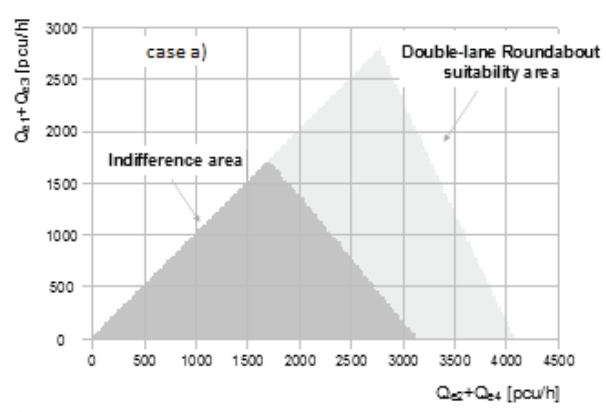

a)

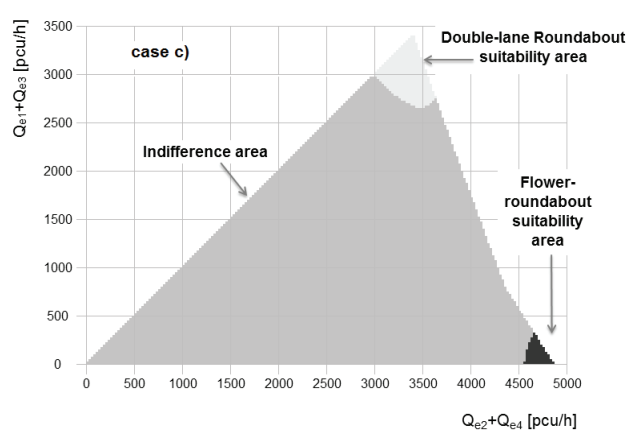

c)

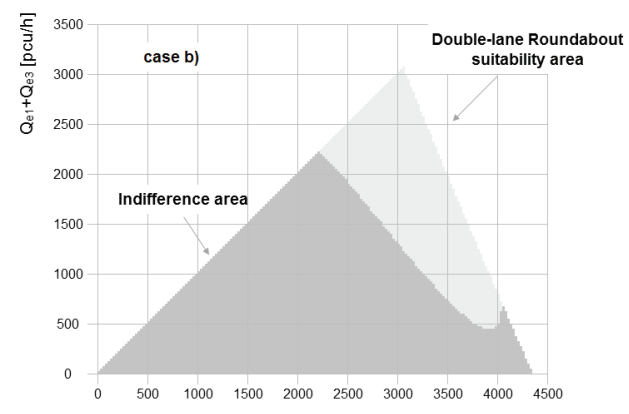

b)

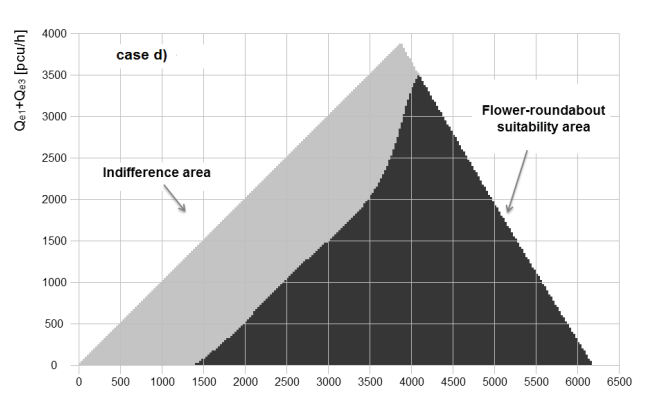

d)

Fig. 3. Suitability domains in undersaturated traffic conditions

Figures $3 \mathrm{a}$ and $3 \mathrm{~b}$ correspond to o-d matrices of traffic flows where percentages of right turners from all legs are equal to $40 \%$ and $50 \%$, respectively. The same Figures $3 \mathrm{a}$ and $3 \mathrm{~b}$ show that the double-lane roundabouts perform better (or offer equivalent performances) than the flower roundabouts (no flower roundabout suitability area exists) for all combinations of entering traffic flows. Indifference areas are present for a wide range of traffic demand, denoting traffic situations without any clear benefits of a roundabout over the other roundabout. On the contrary, benefits for flower roundabouts can be found when percentages of right-turning vehicles are above $60 \%$ percent and reach $70 \%$ of total vehicles entering the roundabout from all legs (see Figures $3 \mathrm{c}$ and $3 \mathrm{~d}$ ).

The graph in Figure 3a, representing traffic situations in which right turning vehicles are $40 \%$ (see the case a in Table 4), shows that the double-lane roundabouts perform more effectively than the flower roundabouts for $\left(\mathrm{Q}_{\mathrm{e} 2}+\mathrm{Q}_{\mathrm{e} 4}\right)>1700 \mathrm{pcu} / \mathrm{h}$ and $\left(\mathrm{Q}_{\mathrm{e} 1}+\mathrm{Q}_{\mathrm{e} 3}\right)>1700 \mathrm{pcu} / \mathrm{h}$. Benefits for double-lane roundabouts over flower roundabouts can be also found when $\left(\mathrm{Q}_{\mathrm{e} 2}+\mathrm{Q}_{\mathrm{e} 4}\right)>3000 \mathrm{pcu} / \mathrm{h}$; combinations of $\left(\mathrm{Q}_{\mathrm{e} 2}+\mathrm{Q}_{\mathrm{e} 4}\right)$ and $\left(\mathrm{Q}_{\mathrm{e} 1}+\mathrm{Q}_{\mathrm{e} 3}\right)$, with values approximately increasing within the range $1700-3000 \mathrm{pcu} / \mathrm{h}$ and 
less than $1700 \mathrm{pcu} / \mathrm{h}$ respectively, can provide both situations in which benefits for the double-lane roundabouts are found and situations in which the two roundabouts have equivalent performances. Moreover, the indifference area, corresponding to situations with equivalent performances for the two roundabouts, is observed when both $\left(\mathrm{Q}_{\mathrm{e} 2}+\mathrm{Q}_{\mathrm{e} 4}\right)$ and $\left(\mathrm{Q}_{\mathrm{e} 1}+\mathrm{Q}_{\mathrm{e} 3}\right)$ assume values less than $1700 \mathrm{pcu} / \mathrm{h}$. Similar considerations can be drawn from the graph in Figure $3 \mathrm{~b}$ corresponding to traffic situations where all right turners percentages are equal to $50 \%$ (see the case $b$ in Table 4). However, the suitability domain of the double-lane roundabout is here less wide than that in Figure 3a, whereas the indifference area, corresponding to situations where no clear benefits of a roundabout over the other one can be deducted, is wider than the case a.

Figure $3 \mathrm{c}$ instead shows that the indifference area is rather wide and this occurs for many combinations of entering flow. Thus, when the case $\mathrm{c}$ in Table 4 is considered, the flower and double-lane roundabout suitability areas are provided for high values of $\left(\mathrm{Q}_{\mathrm{e} 2}+\mathrm{Q}_{\mathrm{e} 4}\right)$ and very low values of $\left(\mathrm{Q}_{\mathrm{e} 1}+\mathrm{Q}_{\mathrm{e} 3}\right)$, and for $\left(\mathrm{Q}_{\mathrm{e} 2}+\mathrm{Q}_{\mathrm{e} 4}\right)$ and $\left(\mathrm{Q}_{\mathrm{e} 1}+\mathrm{Q}_{\mathrm{e} 3}\right)$ values approximately within the range $3000-3500 \mathrm{pcu} / \mathrm{h}$, respectively. At last, when the case $\mathrm{d}$ in Table 4 is considered, the suitability area for the flower roundabout is wide:

- for $\left(\mathrm{Q}_{\mathrm{e} 2}+\mathrm{Q}_{\mathrm{e} 4}\right)>4000 \mathrm{pcu} / \mathrm{h}$ the flower roundabout performs better the double-lane roundabout;

- for $\left(\mathrm{Q}_{\mathrm{e} 2}+\mathrm{Q}_{\mathrm{e} 4}\right)$ values approximately increasing within the range $1500-4000 \mathrm{pcu} / \mathrm{h}$, flower roundabouts have equivalent performances or are more efficient than double-lane roundabouts based on the combination of values assumed by $\left(\mathrm{Q}_{\mathrm{e} 2}+\mathrm{Q}_{\mathrm{e} 4}\right)$ and $\left(\mathrm{Q}_{\mathrm{e} 1}+\mathrm{Q}_{\mathrm{e} 3}\right)$;

- for $\left(\mathrm{Q}_{\mathrm{e} 2}+\mathrm{Q}_{\mathrm{e} 4}\right)<1500 \mathrm{pcu} / \mathrm{h}$ and $\left(\mathrm{Q}_{\mathrm{e} 1}+\mathrm{Q}_{\mathrm{e} 3}\right)<1500 \mathrm{pcu} / \mathrm{h}$, the indifference area appears.

According to the symmetry properties of the graphs in Figure 2, the role of the variables $\left(\mathrm{Q}_{\mathrm{e} 1}+\mathrm{Q}_{\mathrm{e} 3}\right)$ and $\left(\mathrm{Q}_{\mathrm{e} 2}+\mathrm{Q}_{\mathrm{e} 4}\right)$ can be commuted.

\section{Potential Benefits and costs for innovative Roundabout treatments}

In order to assess benefits and costs associated with the construction of a flower roundabout in place of a double-roundabout, geometric feasibility of the flower roundabout should be preliminarily investigated.

Once a site has been determined to be an appropriate candidate for roundabout installation, or enhancement, safety, operational and environmental benefits which the project may realize should be analyzed and estimated; benefits can include reduction in crash frequencies expected with installation of the innovative roundabout instead of the existing double-lane roundabout, but also reduction in delays and emissions. On the other hand, the costs associated with the roundabout project include planning/design costs, construction costs, maintenance costs.

Decision for the layout choice (or conversion of an existing roundabout) should be taken on the basis of a benefit/cost analysis; see e.g. Rodegerdts et al [3] for the applica- 
tion of this method to roundabouts. Very briefly, benefits can include at least those that would help to achieve accident reduction, whereas costs can include initial construction costs, maintenance and operating costs; the benefit/cost ratio is therefore a measure of return, that is the benefit consequent to the expenditure supported.

\subsection{SAfety Benefits}

Safety knowledge on roundabouts has confirmed that these installations may improve the overall safety performance of intersections by eliminating some conflict types, reducing speed differentials, and decreasing speeds as entering users proceed into and through the intersection (see Rodegerdts et al. [3]). Some studies, indeed, have documented an increased safety level at roundabouts due to conflict points lesser than stop-controlled intersections: the number of vehicle-vehicle conflict points for single-lane roundabouts decreases from 9 to 6 at 3-leg intersections, and from 32 to 8 at 4 -leg intersections ( $75 \%$ fewer vehicle conflict points compared to unsignalized stop-controlled intersections).

Double-lane roundabouts, and more, generally, multi-lane roundabouts, have safety characteristics similar to those of single-lane roundabouts; however, the number of conflict points is increased since wider circulatory roadways, as well as additional entry and exit lanes introduce conflicts not present in single-lane roundabouts. Despite the potential for hazardous conflicts such as right angle and left turn head-on crashes is not present at roundabouts, improper lane-use conflicts (users fail to maintain lane position) and improper left turn conflicts (entering next to an exiting vehicle) are present in double-lane roundabout compared to single-lane roundabouts (see Robinson et al [28]).

Crash modification factors for the conversion of a double-lane roundabout in a flower roundabout (i.e. the percentage change in the number of crashes caused by the intervention) are not yet known. Safety improvements associated with the conversion of a double-lane roundabout to a flower roundabout can be considered in terms of reduced number of potential conflict points. It should be noted, indeed, that a flower roundabout can be considered as a single lane roundabout with by-pass for right turns at each entry approach; thus, typical low-speed side-swipe conflicts of double-lane roundabouts are eliminated. Moreover, as for single-lane roundabouts, at flower roundabouts the vehicular crossing conflicts are replaced by merging conflicts. Further safety benefits are: i) weaving conflict points are transferred from the circulatory roadway to the road section before channeling at roundabout entries; ii) right-turners, moving on separated lanes, have no conflicts with circulating vehicles. In this view the conversion of a double-lane roundabout into a flower roundabout can improve the safety performance of the intersection; the effective reduction in the number of crashes will depend on the amount of drivers by maneuvre, that is from the specific o/d matrix, and currently it can be estimated by conflict traffic techniques and/or micro simulation-related approaches. 


\subsection{EnVironmental Benefits}

Generally speaking, the environmental impact of road facilities (road segments or intersections) includes local effects due to noise and water pollution, but also effects on air quality; global effects may include climate change from vehicle emissions, as well as habitat destruction and disturbance that are especially important in and around cities with high traffic volumes. However, environmental benefits to justify the amount of economic investment for any type of road facility have to be necessarily associated with the planning/design phase and assessed on the basis of a sound evaluation.

In the case of minor projects, such as conversion of existing installations to new or innovative types similarly sized, evaluation of environmental benefits can be limited to local effects and quantified in terms of reduced fuel consumption and improved air quality (Rodegerdts et al. [3]).

Benefits on fuel consumption can be estimated in different way, e.g. comparing the estimates of annual vehicle-hours of delay, multiplied to a specified fuel consumption rate during idling and then converted to a cost, assuming an average cost of fuel.

Improved air quality is less readily quantified than reduction in fuel consumption. It is well-known that polluting emissions are dependent on vehicle characteristics and traffic conditions expected after facilities construction and during operations. Vehicle emissions are linked to modal vehicle activity on roads, but still to-day modal emission rate models do not allow proper estimation of on-road vehicle emissions generated from the driving modes (namely acceleration, cruise, deceleration, and idling) occurring at roundabouts. An exploratory analysis led by Giuffrè, Granà, T. Giuffrè, Marino [29] allowed to derive through vehicle emissions models the relative weight of emission factors with reference to traffic events on arterials and freeways; for urban arteries, regardless of the pollutant type, it was demonstrated that the level of total emissions derives from the percentage of time spent in each driving mode and from the level of emissions corresponding to this. It was also highlighted that estimates of vehicle pollutant emissions should be derived from emission factors corresponding to each elementary modal activity and from proportion of time spent by vehicles in each modal activity, such as defined at mesoscopic level. However, the evaluation of emission levels, for each different pollutant, should be mainly standardized through the type of road, volume-to-capacity ratio and fleet composition.

A comparative analysis between conventional and innovative roundabouts in terms of vehicular emissions $\left(\mathrm{CO}, \mathrm{CO}_{2}, \mathrm{NO}\right.$ and $\left.\mathrm{PM}_{2,5}\right)$ was implemented by means of COPERT Software by Guerrieri, Corriere, Parla, Di Vincenzo, Messineo [30]. It was highlighted that no benefits for innovative roundabouts can be quantified in the case of low traffic demand level. In the case of high traffic demand level (up to $450000 \mathrm{veh} / \mathrm{year}$ ), double roundabouts perform better than innovative roundabouts; the latter reach a good level of environmental performances depending on percentages of right-turners. Some studies refer to the effective use of Vehicle Specific Power (VSP) methodology, coupled with second-by-second vehicle's dynamics (speed, acceleration, etc.), usually given by 
micro-simulation tools (Coelho, Farias, Rouphail [31]; Salamati, Coelho, Fernandes, Rouphail, Frey, Bandeira [32]). Recently, Vasconcelos, Bastos Silva, Seco, Fernandes, Coelho [33] applied VSP methodology based on Aimsun trajectory files in estimating emissions at turbo roundabouts.

\subsection{Estimation Costs}

In the planning stage of activities and public works, a summary estimate of costs for the implementation of installation has to be obtained; parametric costs as a function of the spatial context and geometric characteristics of the roundabout have to be adopted. Costs for conversion of traditional roundabouts into innovative roundabouts, as long as for any road facility project, include construction costs and maintenance/operating costs. Construction costs are usually a near-term action which have to be annualized, whereas operations and maintenance costs are usually determined on an annualized basis. To convert construction costs into an annualized value that can be introduced into a benefit-cost analysis, a capital recovery factor should be applied; it is based on interest rate and useful life to convert a present-value cost into an annualized cost over a period of $n$ years.

Taking into account that the conversion of a double-lane roundabout into a flower roundabout consists in accommodating the configuration of an existing intersection rather than designing a new installation, the implementation of a flower roundabout inside an existing double-lane roundabout is a cheap work; indeed, the conversion requires that another circulatory driving lane is obtained (within the available width of the ring) towards the center of the circulatory carriageway and separating islands are prolonged towards the central island (see Figure 1b). Additional costs for flower roundabouts can be associated with the appropriate channeling through curbs at entering lanes which must be provided to facilitate the entry in relation to the desired destination, and with rearranging of redundant surfaces into green areas; further marginal conversion costs are related to the need of re-striping and re-paving.

Maintenance costs (typically including pavement, landscaping, lighting upkeep, etc.) and operating costs for flower roundabout are similar to those of traditional roundabouts. However, construction staging should be also considered during the preliminary design of a flower roundabout built inside a double-lane roundabout, especially if it must be built under traffic.

\section{Discussion and Conclusions}

In this paper a comparative performance analysis between flower roundabouts and double-lane roundabouts was carried out; a framework for cost-benefit analysis in assessing the most appropriate design choice of innovative roundabouts (or the convenience of a conversion), was also outlined. 
Operating performances of the roundabouts were explored for different distributions of traffic demand; suitability domains and/or indifference areas in undersaturated conditions were then constructed.

Headways in circulating streams were modeled through a dichotomic shifted negative exponential distribution (M3); according to this assumption, the Hagring model [22] was applied for entry capacity estimations at double-lane roundabouts where movements facing one and two major traffic streams can coexist. To compare the two intersections, the model was specified for the different traffic schemes. Suitability domains (or indifference areas) were constructed and control delay was used as comparison criterion, because it is related to the level of service.

Despite assumptions may have affected results, they show that operational benefits of flower roundabouts over double-lane roundabouts can occur when percentages of right turning vehicles exceed $60 \%$ and are evident when they reach $70 \%$ of the total value of entering vehicles.

Although each specific case should be studied with reference to its own traffic distribution, methodological considerations and comparisons performed in this paper can guide the choice of a flower roundabout or a double-lane roundabout, and support estimations of operating benefits that can be obtained by the conversion of an existing double-lane roundabout to a new flower roundabout with similar space footprint.

At last, it must be highlighted that the suitability areas in Figure 3 denote situations in which differences in the mean control delay (under the same traffic demand) are lesser than $50 \%$; that is suitability areas denote situations of clear benefits of a scheme over the other. Moreover, no indications on which roundabout should be chosen are given by examining the indifference areas in Figure 3. From a practical perspective, the equivalence in terms of performances gives a great freedom in choosing the technical solution that would be appropriate in case of new roundabout installations. On the contrary, a combination of entering traffic flows within the indifference area represents a situation in which the conversion of an existing roundabout can be an inappropriate choice, also due to the current design constraints.

\section{REFERENCES}

1. L.G.H. ForTuis, Turbo roundabouts. Estimation of capacity, Transportation Research Record 2130, 83-92, 2009.

2. T. Tollazzi, M. RenčEl, S. TuRnšEK, New type of roundabout: Roundabout with "depressed" lanes for right turning - "flower roundabout", Promet - Traffic - Traffico, 23, 5, 353-358.

3. L. Rodegerdts et al., Roundabouts: An Informational Guide, $2^{\text {nd }}$ ed., NCHRP Report 672, Washington DC, USA: Transportation Research Board of the National Academies, 2010.

4. W. BRILon, Turbo-Roundabout: an Experience from Germany. Proceedings of the National Roundabout Conference 2008, Kansas City, Missouri, US, 1-18, 2008.

5. O. Giufrete, A. Granì, T. Giuffrè, R. Marino, How to derive the analytical capacity model for notconventional urban roundabouts, WIT Transactions on the Built Environment, 101, 569-578, 2008. 
6. O. Giuffrè, A. Granḋ, T. Giuffrè, R. Marino, Researching a Capacity Model for Multilane Roundabouts with Negotiation of the Right-of-Way between Antagonist Traffic Flows, Modern Applied Science 6,5, 2-12, 2012.

7. J. Lin, L. Xu, J. Fang, M. Wang, Z. Li, Considering the Pedestrian Crossing Coordinated Control on Multi-leg Roundabouts. Proceedings of $3 \mathrm{rd}$ Int. Conf. on International Conference on Intelligent Computation Technology and Automation (ICICTA 2010), 1, 1023-1026, 2010.

8. F. Corriere, M. Guerrieri, Performance analysis of basic turbo-roundabout in urban context. Procedia: Social and Behavioral Sciences, 53, 622-632, 2012.

9. R. Mauro, M. Guerrieri, Right-turn Bypass Lanes at Roundabouts: Geometric Schemes and Functional Analysis, Modern Applied Science, 7, 1, 1-12, 2013.

10. R. Mauro, M. Guerrieri, Flower Roundabouts: Performances Analysis and Comparison with Conventional Layouts, European Journal of Scientific Research, 94, 2, 242-252, 2013.

11. Y. Yao, L. Xu, Y. QIN, Study on methods of traffic volume observation and calculation at five-leg roundabout, Journal of Wuhan University of Technology (Transportation Science and Engineering), 37, 1, 162-166, 2013.

12. Y.H. Yap, H.M. Gibson, B.J. Waterson, An International Review of Roundabout Capacity Modelling, Transport Reviews, 33, 5, 593-616, 2013.

13. R. Kimber, R. Coombe, The Traffic Capacity of Some Major Priority Junctions, Transport and Road Research Laboratory, Supplementary Report 582, Crowthorne, Berkshire, 1980.

14. W. Brilon, N. Wu, L. Bondzio, Unsignalized intersections in Germany. A state of the art 1997, Proceedings of $3^{\text {rd }}$ Int. Conf. on Intersections without traffic signals, 61-70, Portland, Oregon, USA, 1997.

15. Highway Capacity Manual, TRB, National Research Council, Special Report 209: Washington DC, US, Edition 2010.

16. W. Brilon, M. Vandehey, Roundabouts. The state of the art in German. ITE Journal, 68, 11, 48-54, 1998.

17. A. Pratelli, H.M.N. Al-Madani, Testing for a large roundabouts capacity model: experimental comparisons between Italy and Bahrain, WIT Transactions on the Built Environment 116, 3-15, 2011.

18. H.M.N. Al-Madani, Capacity of Large Dual and Triple-Lanes Roundabouts During Heavy Demand Conditions, Arabian Journal for Science and Engineering 38, 3, 491-505, 2013.

19. R. Mauro, Calculation of roundabouts, Berlin-Heidelberg: Springer, 2010, 169 p., 2010.

20. J.C. TAnner, A theoretical analysis of delay At An Uncontrolled Intersections, Biometrica, 49, 1-2, 163-170, 1962.

21. O. Giuffrè, A. Granì, S. Marino, Turbo-roundabouts vs Roundabouts Performance Level, Procedia, Social and Behavioral Sciences, 53, 590-600, 2012.

22. O. Hagring, A further generalization of Tanner's formula, Transportation Research Part B: Methodological, 32, 6, 423-429, 1998.

23. R.J. Cowan, An extension of Tanner's results on uncontrolled intersections. Queueing Systems: Theory and Applications, 1, 3, 249-263, 1987.

24. L. Vasconcelos, A.B. Silva, A. Seco, J. Silva, Estimating the parameters of Cowan's M3 headway distribution for roundabout capacity analyses, Baltic Journal of Road and Bridge Engineering, 7, 4, 261-268, 2012.

25. Infrastructure and Transport Ministry. Geometric and functional standards for the construction of intersections, Decree April 19, 2006, published in the G.U. 170, 24-07-2006, in Italian.

26. R. Mauro, F. Branco, Comparative analysis of compact multilane roundabouts and turbo-roundabouts, ASCE Journal of Transportation Engineering 136, 4, 316-322, 2010.

27. O. Giuffrè, A. GranÀ, S. Marino, Comparing Performances of Turbo-roundabouts and Double-lane Roundabouts, Modern Applied Science, 6, 10, 70-79, 2012. 
28. B.W. Robinson, et al., Roundabouts: An Informational Guide (1st ed.). FHWA-RD-00-067, Washington DC, USA: Transportation Research Board of the National Academies, 2000.

29. O. Giuffrè, A. Granà, T. Giuffrè, R. Marino, Emission Factors Related To Vehicle Modal Activity, International Journal of Sustainable Development and Planning 6, 4, 447-458, 2011.

30. M. Guerrieri, F. Corriere, G. Parla, D. Di Vincenzo, A. Messineo, Reducing air pollutants through road innovative intersections, Applied Mechanics and Materials, 459, 563-568, 2013.

31. M.C. Coelho, T. L. Farias, N. M. Rouphail, Effect of roundabout operations on pollutant emissions, Transportation Research Part D: Transport and Environment, 11,5, 333-343, 2006.

32. K. Salamati, M.C. Coelho, P.J. Fernandes, N.M. Rouphail, H.C. Frey, J. Bandeira, Emission Estimation at Multilane Roundabouts: Effect of Movement and Approach Lane. TRB $92^{\text {nd }}$ Annual Meeting, Washington, DC, US, Transportation Research Board, 2013.

33. A.L.P. Vasconcelos, A.M.C.B. Bastos Silva, Á.J.M. Seco, P.J. Fernandes, M.C. Coelho, Turbo roundabouts: multicriterion assessment on intersection capacity, safety and emissions. TRB $93^{\text {rd }}$ Annual Meeting, Washington, DC, US, Transportation Research Board, 2014. 